\title{
TRABALHO COLABORATIVO NO ENSINO SUPERIOR: RELATO DE UMA EXPERIÊNCIA DOCENTE
}

\author{
Collaborative work in higher education: a teaching experience report
}

\author{
AMATO, Laura - UNILA ${ }^{31}$
}

\begin{abstract}
RESUMO: O objetivo deste relato é apresentar a experiência docente de uma professora-formadora em regime de ensino colaborativo durante uma disciplina inicial do curso de Letras da Universidade Federal da Integração Latino-Americana - UNILA - ministrada em 2011. Os estudantes ingressantes no referido ano cursariam disciplinas relacionadas ao chamado "Primeiro Ciclo", como América Latina, Língua Adicional e Metodologia e, além disso, teriam uma disciplina voltada a seu curso. O curso de Letras estava com sua grade em formação e discussão, e a primeira disciplina era, na época, "Formação Linguística e Literária da América Latina", ministrada por uma professora de linguística e outra de literatura. Um dos objetivos da disciplina era trabalhar o choque cultural através do discurso dos atores da conquista. O trabalho colaborativo e co-participativo das docentes foi fundamental para se manterem a unidade e a coerência da disciplina.
\end{abstract}

PALAVRAS-CHAVE: Ensino superior; Trabalho colaborativo; Disciplina.

\begin{abstract}
The purpose of this report is to describe the experience of a professor at a Language and Literature undergraduate course at the Federal University of Latin American Integration - UNILA - in 2011 with regard to one of the disciplines taught at the beginning of the course. Students would enroll in disciplines related to what is called "First Cycle", which comprised the following: Latin America, Additional Language and Methodology. In addition, they would start with a discipline especially focused on their course, named "Linguistics and Literary Training in Latin America", which was, at that time, teamtaught by a professor of linguistics and another of literature. One of its goals was working the cultural shock through the speech of the actors of the conquest. The collaborative and cooperative work of both professors was fundamental to maintain the unity and coherence of the discipline.
\end{abstract}

KEY-WORDS: Higher education; Team teaching; Disciplines.

Em 2011, a Universidade Federal da Integração Latino-Americana (UNILA) selecionou seus primeiros alunos para o então bacharelado em Letras - Expressões Artísticas e Literárias. O curso, assim como toda a universidade, estava discutindo a sua proposta pedagógica e reformulando e readequando aquelas propostas elaboradas pela Comissão de Implantação da UNILA (2009) e ao mesmo tempo estava formulando o

\footnotetext{
${ }^{31}$ Doutora em Letras pela UFPR, e professora da Universidade Federal da Integração Latino-Americana.
} 
seu Estatuto. Neste período, todos os alunos ingressantes cursavam o chamado Primeiro Ciclo de Estudos, que compreendia dois semestres letivos e era composto pelas seguintes disciplinas: América Latina (180 horas/aula), Metodologia (60 horas/aula), Seminários Temáticos (60 horas/aula) e Língua Adicional: Português ou Espanhol (120 horas/aula). Além dessas, já no primeiro semestre, os estudantes teriam contato com pelo menos uma disciplina do seu curso de entrada, isto é, deveriam integralizar no semestre de entrada uma disciplina específica (60 horas/aula) na área do seu curso. Para os alunos de Letras, o nome de tal disciplina, à época, era Formação Linguística e Literária da América Latina, no desenvolvimento da qual eles teriam contato com textos (cartas, diários, relatos) dos atores da conquista, ou seja, daqueles que participaram da experiência colonizadora e colonizada da América Latina, como Cristóvão Colombo, Pedro Álvares Cabral, Ruiz de Montoya, Bartolomé de Las Casas, Guaman Poma de Ayala, Inca Garcilaso de La Veja, e estabeleceriam um diálogo contemporâneo sobre as construções discursivas imaginárias do continente elaboradas durante a conquista e a colonização. Era uma disciplina com alto teor reflexivo para alunos recém-chegados ao ambiente universitário, e ao mesmo tempo um trabalho que conversava com outras disciplinas feitas por eles e que tinham como objetivo principal descolonizar (MIGNOLO, 2010) a mente e pensar em uma América Latina pré-hispânica e não eurocêntrica.

A complexidade dessa nova disciplina revelou-se também no momento da escolha do docente que iria assumi-la, pois este deveria demonstrar competência tanto em Literatura quanto em Linguística. A solução adequada foi trabalhar com o que se team teaching. Em sua tese sobre team teaching, Freitas (2004) traduziu a expressão literalmente como 'ensino em time', isto é, uma equipe - no caso, dupla - de professores que se responsabilizariam por ministrar os conteúdos pertinentes às suas especialidades. Freitas (2004, no resumo) explica o que é ensino em time em contraposição ao outro tipo de ensino na citação abaixo:

$\mathrm{O}$ ensino em time é visto como uma modalidade alternativa à organização tradicional de ensino, segundo a qual o professor trabalha de modo isolado em salas de aula insulares, isto é, contidas em si mesmas. Devido a várias possibilidades de configuração que pode assumir, o ensino em time pode ser definido de modo amplo: "Dois ou mais professores se agrupando para um objetivo comum para ajudar a otimizar seu ensino e a aprendizagem de seus alunos" (Anderson et al, 1996:9).

Porém, como a referida disciplina não estava dividida em módulos estanques, mas em conteúdos que ao mesmo tempo em que retomavam uma ordem histórica da 
colonização, buscavam um diálogo com a contemporaneidade, a participação das docentes em um efetivo trabalho de equipe foi fundamental e, para tanto, a observação de cada aula anterior a que ministrariam era fundamental.

Além da observação, outros procedimentos em time/ equipe também se mostraram necessários como a preparação prévia de todas as atividades realizada conjuntamente pelas formadoras, incluindo a elaboração do Plano de Ensino, a escolha dos textos e a elaboração das avaliações. Outros pontos importantes foram a leitura e a discussão compartilhadas dos textos escolhidos, pois tomando como premissas a inexperiência das docentes frente à disciplina e também a nova abordagem proposta, isto é, trabalhar como, a partir da linguagem, a literatura da conquista formou o imaginário de América Latina que temos hoje, a troca entre as docentes só fez enriquecer o conteúdo da disciplina.

Quando as aulas eram ministradas com o conteúdo voltado exclusivamente para a temática linguística/discursiva, esta autora, como docente da disciplina, desenvolvia as atividades estabelecidas no Plano de Ensino e era observada pela sua colega, pois era fundamental que ela não só soubesse o texto que estaria sendo discutido com os alunos, como também acompanhasse as dúvidas que surgiriam. Muitas vezes, devido à programação do Plano de Ensino, apenas uma professora ficava mais de uma aula com os alunos, de modo que somente na última aula a outra docente a acompanhava. Assim, esta poderia continuar com o seu tema e com a sua abordagem de uma forma mais articulada, o que contribuiria para a reflexão dos discentes. Esse resultado foi evidenciado na tese de Freitas (2004) como uma das vantagens do ensino em time na visão dos alunos. Além disso,

$\mathrm{Na}$ melhor das hipóteses, times de ensino são comunidades de aprendizagem-exemplo que geram sinergia por meio da colaboração. Devido ao fato de os frutos de seus esforços serem frequentemente visíveis e uma vez que o entusiasmo dos parceiros é usualmente contagioso, eles oferecem inspiração para que outros se envolvam com colaboração. Certamente, o trabalho em time pode apresentar desafios, tais como a demanda maior de tempo ou o potencial para o conflito entre colegas de time. Todavia, as vantagens usualmente superam as desvantagens, e há muitas maneiras criativas para abordar questões que são levantadas. É importante ressaltar que a experiência em se resolver tais desafios pode tornar o ensino-aprendizagem em time muito mais valioso. (EISEN, 2000 apud FREITAS, 2004, pág, 89).

Esse trabalho colaborativo, portanto, mostrou-se fundamental numa universidade como a UNILA, onde a somatória de especialidades e o trabalho interdisciplinar ajudam a integrar tanto pessoas quanto conhecimento. Esta colaboração, neste momento 
histórico de construção coletiva só corrobora o que foi afirmado pela Comissão de Implantação da UNILA (2009b), buscando uma universidade não diferente, mas diferenciada pelo seu modo de atuação.

\section{REFERÊNCIAS}

ANDERSON, G. et al. Team teaching. York: Stenhouse Publishers, 1996.

COMISSÃO de Implantação da Universidade Federal da Integração Latino-Americana. A UNILA em Construção: um projeto para a América Latina. Foz do Iguaçu: IMEA, 2009.

Iguaçu: IMEA, 2009b.

UNILA. Consulta Internacional. Foz do

EISEN, M.J. The many faces of team teaching and learning: an overview. New Directions forAdult Continuing Education, 87: 5-14, Fall 2000. Disponível em WEBSPIRS <http://200.219.29.133:8590/>. Acesso em 20 abr. 2001.

FREITAS, M. A. Ensino em time por professoras-formadaoras (inglês). Um ritmo constante de fragmentações, fluidez e contradições. Tese de doutorado. Assis: UNESP, 2004.

MIGNOLO, W. Histórias locais/Projetos globais. Colonialidade, saberes subalternos e pensamento liminar. Belo Horizonte: Editora da UFMG, 2010. 